\title{
STUDI LITERATUR: PENGARUH PIJAT REFLEKSI KAKI TERHADAP GANGGUAN TIDUR PADA LANJUT USIA
}

\author{
${ }^{1}$ Chaerun Nissa, ${ }^{2}$ Fauziah H Wada, ${ }^{3}$ Puji Astuti, ${ }^{4}$ Salamah T Batubara, ${ }^{5}$ Ashar Prima \\ ${ }^{1}$ Mahasiswa Program Studi D-3 Keperawatan, Jurusan Keperawatan, STIKes Bani Saleh \\ ${ }^{2}$ Departemen Maternitas, Jurusan Keperawatan, STIKes Bani Saleh \\ ${ }^{3,5}$ Departemen Keperawatan Medikal Bedah, Jurusan Keperawatan, STIKes Bani Saleh \\ ${ }^{4}$ Departemen Antropologi Kesehatan, Jurusan Keperawatan, STIKes Bani Saleh \\ Email: ${ }^{1}$ chaerunnissa48@gmail.com, ${ }^{2}$ fauziah@stikesbanisaleh.ac.id, \\ ${ }^{3}$ pujiastuti@stikesbanisaleh.ac.id,4salamah@stikesbanisaleh.ac.id, \\ "Corresponding Author: ${ }^{5}$ ashar@stikes banisaleh.ac.id
}

\begin{abstract}
ABSTRAK
WHO memprediksikan pada tahun 2020 diperkirakan jumlah lansia Indonesia sekitar 80.000.000 jiwa. Kasus insomnia pada lansia lebih tinggi dibandingkan golongan umur lain, yaitu 12-39\%. Salah satu terapi yang dapat mengatasi gangguan tidur pada lansia yaitu terapi pijat refleksi kaki. Telaah literatur ini bertujuan untuk mengetahui pengaruh pijat refleksi kaki pada lansia yang mengalami gangguan tidur. Desain dalam karya tulis ilmiah ini adalah literatur review pencarian menggunakan electronic data base yaitu ProQuest dan pubmed. Kata kunci yang digunakan dalam pencarian adalah lansia, pijat refleksi kaki, gangguan tidur. Kriteria inklusi yang digunakan pada artikel yaitu dapat diakses full text tersedia berbahasa inggris dan indonesia, tahun jurnal yang digunakan dibatasi sepuluh tahun terakhir. Hasil ditemukan 1 artikel dari google scholar dan 2 artikel dari pubmed membahas tentang keefektifan dari pijat refleksi kaki terhadap peningkatan kualitas tidur pada lansia. Hasil literatur review dari ke tiga artikel menunjukan bahwa pijat refleksi kaki efektif dalam meningkatkan kualitas tidur pada lansia.
\end{abstract}

Kata Kunci : Lansia, Pijat refleksi kaki, Gangguan tidur.

\section{ABSTRACT}

WHO states that Indonesia's population is the fourth largest population after China, India, and the United States. According to the 2013 World Health Statistics data, the population of China is 1.35 billion, India is 1.24 billion, the United States 313 million, and Indonesia is in fourth place with 242 million WHO population predicts that by 2020 the estimated number of Indonesia's elderly will be around 80,000,000. Cases of insomnia in the elderly are higher than in other age groups, which is 12-39\%. One therapy that can overcome sleep disorders in the elderly is foot reflexology massage therapy. This literature review aims to determine the effect of foot reflexology massage in the elderly who experience sleep disorders. The design in this scientific paper is a literature review search using an electronic data base that is ProQuestand pubmed. The keywords used in the search are elderly, foot reflexology, sleep of quality. The inclusion criteria used in the article are full text accessible in English and Indonesian, the year of the journal used is limited to the last ten years. The results found 1 article from Google Scholar and 2 articles from PubMed discussing the effectiveness of foot reflexology massage on improving sleep quality in the elderly. Literature review results from the three articles show that foot reflexology is effective in improving sleep quality in the elderly.

Keyword : Elderly, Foot reflexology, Quality of sleep.

\section{PENDAHULUAN}

Proses menua (aging) adalah proses alami yang dihadapi manusia. Proses menua bukanlah suatu penyakit melainkan proses berkurangnya daya tahan tubuh dalam menghadapi stressor dari dalam tubuh maupun luar tubuh (Azizah L.M, 2011). Salah satu dampak stres yang dialami oleh lansia adalah adanya perubahan gangguan tidur antara lain insomnia, hipersomnia, dan gangguan siklus tidur bangun (Sofiana E, 2014).

Sebelas persen dari 6,9 milyar penduduk dunia adalah lansia (WHO, 2013). Lansia di Indonesia cenderung memiliki tingkat kesejahteraan dan kesehatan yang rendah dengan jumlah lansia yang terus bertambah (Adriani dan Wirjatmadi, 2012). WHO memprediksikan pada tahun 2020 
diperkirakan jumlah lansia Indonesia sekitar 80.000.000 jiwa (WHO, 2017).

Insomnia pada lansia disebabkan oleh beberapa faktor, yaitu faktor status kesehatan, penggunaan obat-obatan, kondisi lingkungan, stres psikologis, diet/nutrisi, gaya hidup menyumbangkan insomnia pada usia lanjut (Prananto, 2016). Gangguan tidur berdampak pada kehidupan sosial penderita, psikologis, fisik, dan ekonomi. Dampak dari insomnia cukup berat, diantaranya adalah hilangnya produktivitas dan biaya pengobatan pada pelayanan kesehatan. Selain meningkatkan risiko penyakit generatif seperti hipertensi dan jantung, depresi dan stres ternyata juga merupakan manifestasi gangguan tidur (Ghaddafi , 2010). Gangguan tidur juga meningkatkan risiko terjatuh pada lansia (Helbig et al, 2013) serta keinginan bunuh diri dan penyalahgunaan obat (Nadorff et al, 2013).

Terapi untuk penanganan gangguan tidur dibagi menjadi 2 jenis, yaitu terapi farmakologis dan non-farmakologis. Terapi farmakologis yang digunakan adalah pengobatan utama dalam penanganan gejala insomnia. Obat-obatan ini termasuk sedativehypnotic, antihistamin, antidepresan, antipsikotik dan antikonvulsan. Masalah yang terjadi pada lansia yang mengalami gangguan tidur diperlukan penanganan atau sikap yang tepat untuk mengatasinya dengan tindakan non farmakologis yaitu pijat refleksi kaki (Gehrman dan Ancoli-Israel, 2010). Terapi pijat kaki merupakan salah satu massage therapy yang dapat menyembuhkan hampir semua penyakit, serta merupakan terapi yang aman dan tanpa efek samping (Pamungkas, 2010).

Manfaat pijat refleksi untuk kesehatan sudah tidak perlu diragukan lagi. Salah satu khasiatnya yang paling populer adalah untuk mengurangi rasa sakit pada tubuh. Manfaat lainnya adalah mencegah berbagai penyakit, meningkatkan daya tahan tubuh, membantu mengatasi stress, meringankan gejala migrain, membantu penyembuhan penyakit kronis, dan mengurangi ketergantungan terhadap obat obatan (Prima, Pangastut, Setiyarini, \& Effendy, 2020; Wahyuni, 2014).

\section{METODE}

a. Formulasi PICO

Lansia akan mengalami berbagai penyakit salah satunya yaitu gangguan tidur. Dampak yang disebabkan dari insomnia cukup berat yaitu meningkatnya risiko penyakit generatif seperti hipertensi dan jantung, depresi, stres (Ghaddafi, 2010) juga dapat berisiko terjatuh pada lansia (Helbig et al, 2013) serta keinginan bunuh diri dan penyalahgunaan obat (Nadorff et al, 2013) sehingga diperlukan terapi komplementer yaitu salah satunya dengan pijat refleksi kaki (Gehrman dan Ancoli-Israel, 2010). Untuk mengetahui evidence based tentang pijat refleksi kaki pada lansia yang mengalami gangguan tidur maka dilakukan pencarian literatur dengan formulasi PICO sebagai berikut:

\section{Population : Lansia \\ Intervention : Pijat refleksi kaki \\ Comparisson :- \\ Outcome : Gangguan tidur}

Berdasarkan formulasi PICO diatas maka penulis merumuskan research question yaitu apakah penerapan pijat refleksi kaki dapat berpengaruh pada lansia yang mengalami gangguan tidur?

b. Strategi Pencarian

Pencarian literatur dilakukan dengan mencari publikasi artikel dari literatur pendidikan kesehatan dan medis, pencarian dilakukan pada database: pubmed/ncbi dan ProQuest. Pencarian literatur menggunakan keyword: elderly and foot reflexology and quality of sleep dari hasil pencarian di database, ditemukan ProQuest (1.980), pubmed (10).

Setelah itu dilakukan pembatasan tahun dengan rentang 10 tahun terakhir dan didapatkan 1.280 artikel pada ProQuest dan 5 artikel pada pubmed, lalu membaca judul satu persatu juga melakukan pemilahan jurnal sesuai dengan kriteria inklusi yaitu dapat diakses full text tersedia berbahasa inggris dan indonesia, artikel yang digunakan dibatasi sepuluh tahun terakhir (2011-2020), hanya didapatkan dari ProQuest 15 artikel. 
c. Tabel Deskripsi Ringkasan Artikel

Tabel 1. Tabel Deskripsi Ringkasan Artikel

\begin{tabular}{|c|c|c|c|c|}
\hline Jurnal biography & Population & Intervensi & Comperator & Outcome \\
\hline $\begin{array}{l}\text { Effects of } \\
\text { Reflexology on } \\
\text { Sleep Quality of } \\
\text { Elderly Women } \\
\text { Undergoing } \\
\text { Abdominal Surgery } \\
\text { Author : } \\
\text { Azadeh et al (2016) }\end{array}$ & $\begin{array}{l}80 \text { wanita lansia } \\
\text { menjalan } \\
\text { ioperasi } \\
\text { abdomen dipilih } \\
\text { berdasarkan } \\
\text { kuesioner } \\
\text { kualitas tidur } \\
\text { dengan metode } \\
\text { purposive } \\
\text { sampling } \\
\text { diantara semua } \\
\text { wanita lansia } \\
\text { yang menjalani } \\
\text { operasi pada } \\
\text { abdomen pan } \\
\text { tahun 2015. }\end{array}$ & $\begin{array}{l}\text { Intervensi } \\
\text { keperawatan yang } \\
\text { diberikan adalah } \\
\text { refleksi kaki } 2 \\
\text { kali sehari }(20 \\
\text { menit setiap kali } \\
\text { pemijatan), } 1 \text { kali } \\
\text { dipagi hari (satu } \\
\text { jam setelah } \\
\text { sarapan) dan } 1 \\
\text { kali di malam hari } \\
\text { (sebelum tidur) di } \\
\text { hari kedua dan } \\
\text { ketiga setelah } \\
\text { operasi. }\end{array}$ & $\begin{array}{l}\text { Pada kelompok } \\
\text { kontrol dilakukan } \\
\text { pemijatanr efleksi } \\
\text { kaki tetapi tidak } \\
\text { adanya penjelasan } \\
\text { waktu pemberian } \\
\text { terapi, tidak adanya } \\
\text { penjelasan bahan } \\
\text { yang digunakan, } \\
\text { dan tidak dijelaskan } \\
\text { lamanya pemberian } \\
\text { intervensi. }\end{array}$ & $\begin{array}{l}\text { Hasil penelitian ini } \\
\text { menunjukan bahwa } \\
\text { setelah dilakukan } \\
\text { intervensi } \\
\text { menunjukan hasil } \\
\text { yang signifikan } \\
\text { yaitu (P-nilai < } \\
\text { 0,001) dapat } \\
\text { dikatakan bahwa } \\
\text { pijat refleksi kaki } \\
\text { efektif dalam } \\
\text { perbaikan kualitas } \\
\text { tidur pada wanita } \\
\text { lansia yang } \\
\text { menjalani operasi } \\
\text { abdomen. }\end{array}$ \\
\hline $\begin{array}{lr}\text { Pengaruh } & \text { Massage } \\
\text { Kaki } & \text { terhadap } \\
\text { Penurunan } & \\
\text { Insomnia } & \text { pada } \\
\text { Lansia di } & \text { Banjar } \\
\text { Temesi } & \text { Desa } \\
\text { Temesi Kabupaten } \\
\text { Gianyar } \\
\text { Author : } \\
\text { Putu et al }(2020)\end{array}$ & $\begin{array}{l}\text { Populasi lansia } \\
\text { sebanyak } 23 \\
\text { orang. Dengan } \\
\text { menggunakan } \\
\text { sampel } \\
\text { sebanyak } 15 \\
\text { orang diambil } \\
\text { secara purposive } \\
\text { sampling. }\end{array}$ & $\begin{array}{l}\text { Dengan } \\
\text { mengukur } \\
\text { kualitas tidurnya } \\
\text { hanya } \\
\text { menggunakan } \\
\text { lembar observasi } \\
\text { yang berisi } \\
\text { pertanyaan } \\
\text { tentang apakah } \\
\text { anda mengalami } \\
\text { insomnia atau } \\
\text { tidak } \\
\end{array}$ & $\begin{array}{l}\text { elompok } \\
\text { tidakme } \\
\text { ntervensi }\end{array}$ & \begin{tabular}{lr}
\multicolumn{2}{l}{ Setelah dilakukan } \\
intervensi & pijatre \\
fleksi kaki & terjadi \\
penurunan & \\
insomnia & yaitu \\
sebanyak & 13 \\
respinden & $(86,7 \%)$ \\
mengalami & \\
\multicolumn{2}{l}{ insomnia ringan. }
\end{tabular} \\
\hline $\begin{array}{l}\text { The Effect of Foot } \\
\text { Reflexology } \\
\text { Massage on the } \\
\text { Sleep Quality of } \\
\text { Elderly Women } \\
\text { With Restless Leg } \\
\text { Syndrome } \\
\text { Author: } \\
\text { Abbasi et al (2018) }\end{array}$ & $\begin{array}{l}67 \text { wanita lansia } \\
\text { dengan sindrom } \\
\text { kaki gelisah }\end{array}$ & $\begin{array}{l}\text { Dilakukan } \\
\text { sebanyak } 8 \text { sesi } \\
\text { selama } 20 \text { menit } \\
(10 \text { menit untuk } \\
\text { setiap kaki) } \\
\text { selama } 4 \text { minggu. }\end{array}$ & $\begin{array}{l}\text { Tidak } \\
\text { kelompok } \\
\text { dalam } \\
\text { ini. }\end{array}$ & $\begin{array}{lr}\text { Setelah } & \text { dilakukan } \\
\text { intervensi } & \text { pijat } \\
\text { refleksi } & \text { kaki } \\
\text { hasilnya } & \text { signifikan } \\
\text { yaitu } & (\mathrm{p}<0,001) \\
\text { Dapat disimpulkan } & \\
\text { bahwa pijat refleksi } & \text { kaki memiliki efek } \\
\text { positif } & \text { pada } \\
\text { kualitas } & \text { tidur } \\
\text { wanita ransia } & \text { langan sindrom } \\
\text { dengan } & \text { kaki gelisah. }\end{array}$ \\
\hline
\end{tabular}




\section{HASIL DAN PEMBAHASAN}

Setelah dilakukan pencarian menggunakan kriteria inklusi dan eksklusi didapatkan 3 jurnal full text yang sesuai kriteria validitas dan relevansi yang baik.

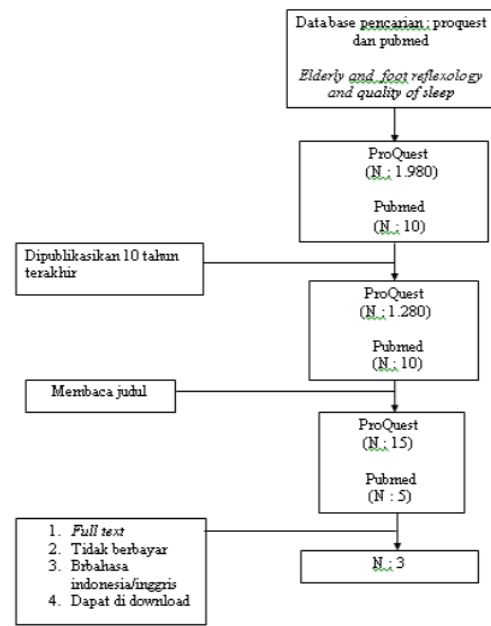

Gambar 1. Searching Strategy Flow Chart

Pembahasan hasil telaah evidance base berdasarkan teori dan hasil penelitian didapatkan hasil sebagai berikut:

a. Karakteristik Responden

Hasil penelitian yang dilakukan oleh Azadeh et al, penelitian dilakukan pada tahun 2016, tidak dicantumkan umur pada artikel ini. Sementara penelitian yang dilakukan oleh (Putu et al, 2020) penelitian dilakukan sebanyak 15 orang pada jenis kelamin lakilaki $11(73,3 \%)$, usia dari 60-74 tahun 13 orang $(86,7 \%)$, Sebelum dilakukan pemijatan terdapat lansia yang mengalami insomnia rendah 6 orang, dan insomnia sedang 9 orang (60\%). Setelah dilakukan pemijatan lansia yang tidak insomnia terdapat 2 orang, dan insomnia rendah 13 orang $(86,7 \%)$. Penelitian yang dilakukan oleh (Abbasi et al, 2018) melakukan penelitian pada responden 67 wanita lansia dengan sindrom kaki gelisah, tidak dicantumkan umur pada penelitian ini.

\section{b. Intervesi dan Instrumen}

Penerapan intervensi yang dilakukan beranekaragam, menunjukan bahwa intervensi yang dilakukan oleh Azadeh et al, pada kelompok control tidak menerim aintervensi apapun. Sedangkan kelompok eksperimen menerima intervensi refleksi. Sedangkan kelompok eksperimen menerima intervensi refleksi kaki 2 kali sehari (20 menit setiap kali pemijatan), 1 kali dipagi hari (satu jam setelah sarapan) dan 1 kali di malam hari (sebelum tidur) di hari kedua dan ketiga setelah operasi. Penelitian ini dilakukan dengan dipilihnya responden berdasarkan kuesioner kualitas tidur dengan metode purposive sampling diantara semua wanita tua yang menjalani operasi abdomen pada tahun 2015. Instrumen yang digunakan dalam penelitian ini adalah Pittsburg Sleep Quality Index (PSQI).

Sementara pada penelitian yang dilakukan oleh Putu et al, dalam mengukur kualitas tidurnya hanya menggunakan lembar observasi yang berisi pertanyaan tentang apakah anda mengalami insomnia atau tidak.

Selanjutnya intervensi yang dilakukan oleh Abbasi et al, pijat refleksi kaki dilakukan selama delapan sesi selama 20 menit (10 menit untuk setiap kaki) selama 4 minggu, durasi pijat untuk setiap kaki ditetapkan untuk 10 menit, karena intensifikasi gejala pada sore hari, terjadi sekitar 3-7 jam. Setiap wanita lansia menerima pijat di tempat tidur nyaman mereka sendiri di tempat yang tenang. Pertama, pijat umum dilakukan dengan lotion selama 5 menit, dan kemudian titik kelenjar pineal di bagian luar jempol kaki dipijat selama 5 menit. Pijat dilakukan dikecepatan lambat dengan irama teratur dan dengan kedalaman itu dapat/ditoleransi oleh pasien. Post-test diberikan pada minggu kelima setelah akhir intervensi dan hasilnya dianalisis. Instrumen yang digunakan yaitu Pittsburg Sleep Quality Index (PSQI) dan kuesioner demografis digunakan untuk mengumpulkan data yang diberikan sebelum dan sesudah intervensi.

c. Efektivitas Pijat Refleksi Kaki Pada Lansia Yang Mengalami Gangguan Tidur

Hasil penelitian yang dilakukan oleh Azadeh et al tahun 2016, dapat disimpulkan bahwa pijat refleksi kaki signifikan dalam meningkatkan kualitas tidur pada lansia dan untuk mengurangi rasa sakit pasca operasi dengan $(\mathrm{P}<0,001)$. Sementara dalam penelitian yang dilakukan oleh Putu et al tahun 2020, berdasarkan uji statistik wilcoxon didapatkan hasil bahwa nilai $\mathrm{P}+$ value $+0,001$ yang berarti $\mathrm{P}<\alpha(0,05)$ juga menunjukan hasil yang sama. 
Hasil penelitian yang mendukung penelitian diatas yaitu dengan dilakukannya oleh (Abbasi et al, 2018, juga menunjukan bahwa pijat refleksi kaki efektif dalam meningkatkan kualitas tidur dan mengurangi nyeri pada sindrom kaki gelisah dengan $(\mathrm{P}$ $<0,001)$.

Menurut beberapa penelitian lain menunjukan bahwa pijat kaki juga meningkatkan sekresi hormon seperti dopamin dan serotonin, yang memiliki peran utama adalah menciptakan euforia dan kebahagiaan pada orang, dan akibatnya mengurangi kecemasan pasien, menekan kecemasan dapat secara langsung mempengaruhi dan meningkatkan kualitas tidur (McGowan et al, 2016).

Pijat refleksi kaki memberikan rangsangan berupa tekanan pada syaraf pada telapak kaki. Rangsangan tersebut diterima tekanan pada saraf padat elapak kaki. Rangsangan tersebut diterima oleh reseptor saraf (saraf penerima rangsangan). Rangsangan yang diterima ini akan diubah oleh tubuh menjadi aliran listrik, kemudian aliran listrik tersebut langsung dikirim keotak. Sinyal yang dikirim langsung keotak dapat melepaskan ketegangan dan memulihkan keseimbangan keseluruh tubuh (Dewi \& Hartati, 2015).

\section{KESIMPULAN}

Berdasarkan hasil Studi Literature dapat disimpulkan bahwa dari 3 artikel menyatakan bahwa pijat refleksi kaki secara signifikan efektif dalam memperbaiki kualitas tidur lansia.

\section{REFERENCES}

Abbasi Fakhravari, A., Bastani, F. \& Haghani, H. 2018. The Effect of Foot Reflexology Massage on the Sleep Quality of Elderly Women With Restless Leg Syndrome. Journal of ClientCentered Nursing Care, 4(2), pp. 96103.

https://doi.org/10.32598/jccnc.4.2.96

Adriani, M., dan B. Wirjatmadi. 2012. Peranan Gizi dalam Siklus Kehidupan. Edisi Pertama. Kencana. Jakarta: 394 419.

Azizah, L.M. 2011. Keperawatan lanjut usia. Graha Ilmu: Yogyakarta.
Dewi \& Hartati. 2015. Pijat Refleksi + Obat Herbal. Yogyakarta : MediaBook

Ghaddafi , M. 2010. Tatalaksana Insomnia dengan Farmakologi atau NonFarmakologi. E-Jurnal Medika Udayana, 4: 1-17.

Gehrman, P. dan S. Ancoli-Israel. 2010. Insomnia in the Elderly. Dalam Insomnia Diagnosis and Treatment. Editor M.J. Sateia dan D.J. Buysse. Informa Health. New York: 90-91.

Helbig, A.K., A. Doring, M. Heier, R.T. Emeny, A-K. Zimmermann, C.S. Autenrieth, K-H. Ladwig, E. Grill, C. Meisinger. 2013. Association between Sleep Disturbance and Falls among the Elderly: Results from the German Cooperative Health Research in the Region of Augsburg-Age Study. Sleep Medicine, 14: 1356-1363.

Kheyri, A, Bastani, F \& Haghani, H. 2016. 'Effects of reflexology on sleep quality of elderly women undergoing abdominal surgery', Journal of Client-Centered Nursing Care, vol. 2, no. 1, pp. 11-18.

McGowan, SK, Espejo, EP, Balliett, N \& Werdowatz, EA 2016, 'The effects of transdiagnostic group CBT for anxiety on insomnia symptoms', Cognitive Behaviour Therapy, vol. 45, no. 2, pp. 163-75.

Nadorff, M.R., A. Fiske, J.A. Sperry, R. Petts, J.J. Gregg. 2013. Insomnia Symptoms, Nightmare and Suicidal Ideation in Older Adults. The Journal of Gerontology, 68: 145-152.

Pamungkas, R (2010) Dahsyatnya Jari Refleksi Yogyakarta Pinang Merah.

Prananto. 2016. Mengenal Sebab-Sebab, Akibat-Akibat, Dan Cara Terapi Insomnia. Yogyakarta: FlashBooks.

Prima, A., Pangastut, H. S., Setiyarini, S., \& Effendy, C. 2020. The Effectiveness of Foot Re lexology Massage in Reducing Cortisol Saliva Levels as a Biomarker of Stress for Patients with Cancer. International Journal of Research in Pharmaceutical Science, 11(4), 75777584.

https://doi.org/https://doi.org/10.26452/ij rps.v11i4.3965

Putu Widiana et al. 2020. Pengaruh Massage Kaki terhadap Penurunan Insomnia pada Lansia di Banjar Temesi Desa Temesi 
Kabupaten Gianyar. Jurnal Akademika Wahyuni, S. 2014. Pijat refleksi untuk Baiturrahim Jambi, Vol 9, No. 1, Maret 2020.

Sofiana, E. 2014. Hubungan Tingkat Stres Dengan Kejadian Insomnia Pada Lansia di Desa Tahunan Kabupaten Jepara. Kudus: Program Studi Ilmu Keperawatan STIKes Cendekia Utama kesehatan. Jakarta Timur : Dunia Sehat. WHO. 2013. World health statistics 2013. Geneva: WHO press.

WHO. 2017. Older People and Primary Health Care (PHC). Diakses Tanggal 13 Setember, 2017.

Kudus.

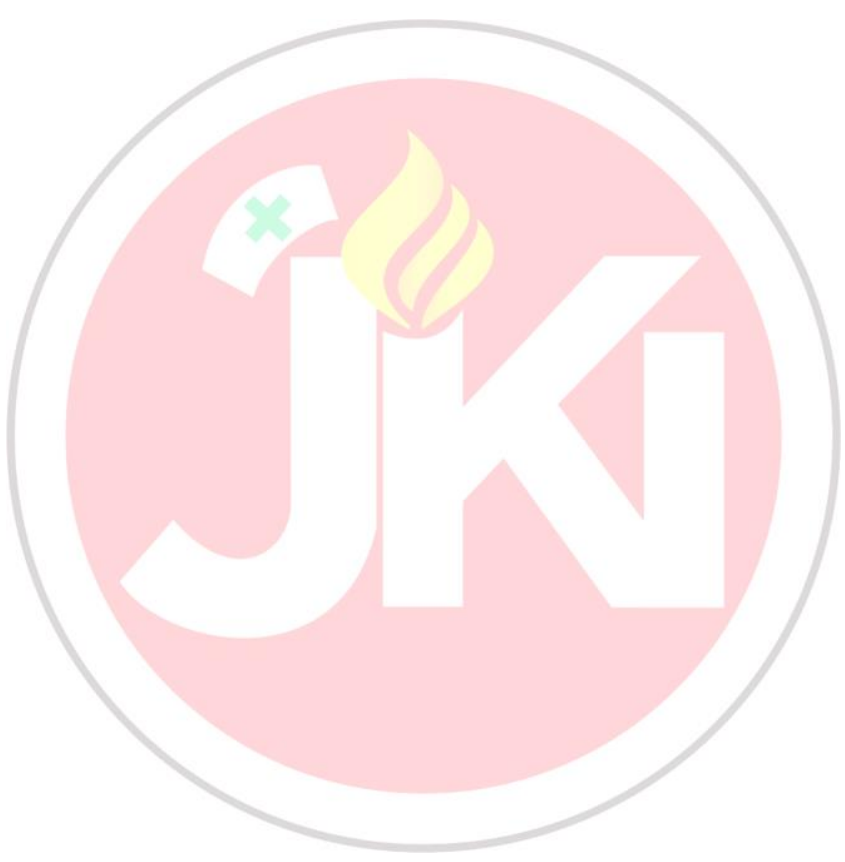

